\title{
Escala de Identidade Profissional de Professores de Educação Física: Procedimentos de construção e validação
}

\author{
Scale of Professional Identity of Physical Education Teachers: \\ Development and validation procedures
}

\author{
José António Marques Moreira, ${ }^{1 *}$ António Gomes Ferreira, ${ }^{2}$ Joaquim Armando Ferreira ${ }^{2}$ \\ ARTIGO ORIGINAL | ORIGINAL ARTICLE
}

\begin{abstract}
O presente estudo descreve os procedimentos da construção de uma escala de identidade profissional de professores da área da educação física e as suas qualidades psicométricas. Depois de breves considerações sobre o construto e sua operacionalização, realizou-se a análise dos procedimentos da sua construção e procedeu-se à análise de validade de construto (análise fatorial) e à análise da consistência interna através do cálculo do coeficiente alfa de Cronbach. Depois de realizado um pré-teste, e, posteriormente, administrada a escala a uma amostra de 206 professores de educação física, concluiu-se que o instrumento possui qualidades psicométricas satisfatórias. A análise da consistência interna dos dois fatores identificados revelou que se trata de um instrumento fidedigno. Assim, uma vez que estes fatores se apresentam internamente consistentes e bem definidos pelos itens e logicamente, concluímos que a escala revela qualidades psicométricas que recomendam o seu uso como instrumento de investigação. Para além de bons indicadores de validade, as medidas aplicadas caraterizam-se por uma fidelidade boa ou adequada e estruturas fatoriais interpretáveis, sugerindo que avaliam, de forma consistente, as variáveis que pretendem medir, constituindo-se como um instrumento adequado para avaliar a identidade profissional dos professores de educação física.

Palavras-chave: identidade docente, educação física escolar, escala de avaliação
\end{abstract}

ABSTRACT

This paper reports the procedures to design a physical education teachers' professional identity scale and its psychometric features. After reflecting on the construct and its operationalisation, we analyzed the procedures required for its design and validity of the construct (factorial analysis) and analyzed the internal consistency by calculating the Cronbach alpha coefficient. After carrying out a pre-test and then administering a scale to a sample of 206 physical education teachers, we concluded that the instrument has satisfactory psychometric qualities. The analysis of the internal consistency of the two factors identified showed that the instrument is reliable. Thus, because these factors are internally consistent and well defined by the items, we concluded that the scale has psychometric qualities that support its use as a reliable research instrument. Further to providing good validity indicators, the measures applied are characterized by being reliable or adequately reliable and having interpretable factorial structures, suggesting that they consistently assess the variables they intend to measure, thus being an appropriate instrument to assess the professional identity of physical education teachers. Keywords: teaching identity, school physical education, assessment scale

Artigo recebido a 25.05.2013; $1^{\text {a }}$ Revisão 05.09.2013; $2^{\text {a }}$ Revisão 13.01.2014; Aceite 16.02.2014

${ }^{1}$ Departamento de Educação e Ensino à Distância, Universidade Aberta, Lisboa, Portugal

${ }^{2}$ Faculdade de Psicologia e Ciências da Educação da Universidade de Coimbra, Coimbra, Portugal

* Autor correspondente: Universidade Aberta, Departamento de Educação e Ensino à Distância, Rua do Amial, n. ${ }^{\circ} 752$, 4200-055 Porto - Portugal; E-mail: jmoreira@uab.pt 


\section{INTRODUÇÃO}

A educação física em Portugal nos últimos 70 anos tem sido marcada por muitas mudanças que têm influenciado o seu rumo concetual e metodológico (Oliveira, 2012), com reflexos evidentes na construção e desenvolvimento da identidade profissional dos professores desta área (Ferreira \& Moreira, 2010, 2012; Ferreira, Moreira \& Ferreira, 2011; Moreira \& Ferreira, 2011, 2012). Nesse sentido procurámos desenvolver um estudo que indagasse a forma como os professores de educação física provindo de diferentes escolas de formação existentes em Portugal desde a criação do Instituto Nacional de Educação Física, que se afirmou como a primeira grande escola de formação de professores desta área, na década de 40 do século $\mathrm{XX}$, se percecionam e se avaliam enquanto docentes; como se percecionam relativamente a colegas do grupo disciplinar, a colegas de profissão de outros grupos disciplinares, aos seus alunos e a outros profissionais; ou como definem a sua profissão. Após uma análise exaustiva da literatura acerca do fenómeno identitário construto em questão, verificámos a inexistência de instrumentos que nos permitissem avaliar a identidade profissional dos professores deste grupo disciplinar, que apresenta algumas especificidades devido à natureza da disciplina. Assim, baseados na literatura e na revisão de estudos na área, sobretudo no quadro concetual definido por Kelchtermans (1993, 1995) operacionalizámos o conceito de identidade profissional em três dimensões: a dimensão motivacional, relativa ao projeto profissional e incidindo na escolha da docência e na motivação para a mesma; a dimensão representacional, relacionada com a perceção profissional, no plano da imagem de si enquanto professor e da imagem da profissão; e a dimensão socioprofissional, localizada aos níveis social e relacional, baseando-se sobretudo nos processos de socialização profissional.

Após a definição deste quadro concetual e de ter realizado um conjunto de 15 entrevistas (semiestruturadas) a professores de educação física de diferentes escolas de formação inicial, que procurou definir um quadro empírico e interpretativo das opiniões destes professores, partimos para a construção de uma escala que nos permitisse avaliar as diferentes dimensões da identidade profissional dos professores deste grupo disciplinar. São as principais etapas e procedimentos da construção dessa escala, que intitulámos de Escala de Identidade Profissional de Professores de Educação Física (EIP$\mathrm{PEF}$ ) e as suas qualidades psicométricas, que iremos aqui apresentar.

Assim, neste estudo descreveremos os principais procedimentos relativos à sua construção e validação, tendo como referência: as etapas da sua conceção, o que mede especificamente; o tipo de operacionalização que representa; a análise de validade de construto e a análise da consistência interna, através do cálculo do coeficiente alfa de Cronbach.

\section{MÉTODO}

\section{Pré Teste: amostra e procedimentos}

Após a definição de um sistema de categorias, resultante do quadro concetual existente e da análise de um conjunto de entrevistas que realizámos previamente, procurando definir um quadro categorial interpretativo das opiniões dos professores a nível do construto analisado, definimos um conjunto de itens relativos a esta categorização. Assim, a Escala de Identidade Profissional dos Professores de Educação Física (EIPPEF) ficou com 40 itens, sendo composta exclusivamente, por respostas fechadas e estruturadas segundo o modelo da escala de Likert. Depois da sua elaboração, a escala foi testada, junto de 8 professores especialistas, com o intuito de verificar, entre outros aspetos, se todas as questões eram compreendidas pelos inquiridos, se não haveria perguntas inadequadas à informação pretendida ou repetitivas, se não faltariam itens relevantes ou se os inquiridos não considerariam a escala demasiado longa e difícil. Para além destes aspetos de natureza estrutural, a nossa intenção com a testagem foi, também, avaliar os seus índices psicométricos. Este procedimento permitiu, também, averiguar as condi- 
ções em que a escala deveria ser aplicada, a sua qualidade gráfica e a adequação das instruções que a acompanham. Este grupo de professores foi encorajado a fazer observações e sugestões respeitantes à estrutura da escala e a cada uma das suas perguntas.

De seguida, conduziu-se um pré-teste, sendo a escala aplicada a uma amostra de 40 professores de Educação Física dos $2 .^{\circ}$ e $3 .^{\circ}$ ciclos do Ensino Básico e Ensino Secundário de escolas dos distritos de Bragança e do Porto, pertencentes à população do inquérito (mas que não fizeram parte da amostra selecionada).

Dos 40 professores iniciais a nossa amostra ficou reduzida a 33, devido à omissão de dados pessoais ou profissionais e/ou por falta ou duplicação de respostas a alguns itens da escala e cuja caracterização por sexo, idade, instituição de formação inicial, tempo de serviço, situação profissional e habilitações académicas se encontra sistematizada na Tabela 1.

Procedemos, depois, à análise de consistência interna da escala global e das diferentes dimensões da EIPPEF, que veio a revelar uma boa consistência interna com um valor de 0.87 , enquanto as diferentes dimensões, Motivacional, Representacional e Socioprofissional, apresentaram respetivamente valores de $0.76,0.54$ e 0.29. Partindo do pressuposto que um instrumento que apresente uma consistência interna de 0.70 (Cronbach, 1984; Nunnally, 1978) pode ser considerado adequado para avaliar a variável que se pretende medir, considerámos que o instrumento apresentou, nesta fase, uma consistência interna adequada.

Com o intuito de aumentar o coeficiente de fiabilidade, calculámos a correlação item/ questionário e, para uma análise mais precisa, relativa a cada uma das dimensões do instrumento, calculámos ainda a correlação item/ dimensão, isto porque assumindo que cada item contribui para a formação da atitude que se quer medir deve, pois, existir uma correlação estatisticamente significativa e relativamente forte entre cada item e o total (Oppenheim, 1979). No processo de validação de instrumento, a análise da correlação de cada item com o total da escala a que pertence, excluindo o item em causa, é sempre efetuada no sentido de escolher os melhores itens (Nunnally, 1978). Para um maior rigor na sua seleção, alguns autores consideram, também, que os itens devem apresentar correlações com o total da escala superiores a 0.30 (Cronbach, 1984; Nunnally, 1978).

Tabela 1

Caracterização da amostra (Pré-Teste)

\begin{tabular}{|c|c|c|}
\hline & $\mathrm{n}$ & $\%$ \\
\hline \multicolumn{3}{|l|}{ Sexo } \\
\hline Masculino & 19 & 57.6 \\
\hline Feminino & 14 & 42.4 \\
\hline \multicolumn{3}{|l|}{ Idade } \\
\hline 26 a 35 anos & 12 & 36.4 \\
\hline 36 a 45 anos & 14 & 42.4 \\
\hline 46 a 55 anos & 7 & 21.2 \\
\hline \multicolumn{3}{|c|}{ Instituição de Formação Inicial } \\
\hline ISEF & 4 & 12.1 \\
\hline Outras Faculdades & 17 & 51.5 \\
\hline ESEs & 12 & 36.4 \\
\hline \multicolumn{3}{|l|}{ Tempo de Serviço } \\
\hline$<5$ anos & 3 & 9.0 \\
\hline 6 a 15 anos & 16 & 48.5 \\
\hline 16 a 25 anos & 9 & 27.3 \\
\hline 26 a 35 anos & 5 & 15.2 \\
\hline \multicolumn{3}{|l|}{ Situação Profissional } \\
\hline Efetivo & 5 & 15.2 \\
\hline Contratado & 28 & 84.8 \\
\hline \multicolumn{3}{|l|}{ Habilitações Académicas } \\
\hline Licenciatura & 29 & 87.9 \\
\hline Mestrado & 4 & 12.1 \\
\hline
\end{tabular}

Os resultados da análise da consistência interna da EIPPEF, com 40 itens, sugeriram a eliminação do item 3 que apresentou um valor de 0.201. Apesar de outros itens apresentarem uma correlação fraca, e estarem próximos dos valores críticos, considerámos que, por exemplo, os itens 12, 25 e 31 não deviam ser rejeitados nesta fase, porque apresentaram validade de conteúdo, medindo diretamente aspetos ligados às dimensões em questão. 
Após a eliminação do item 3 a EIPPEF ficou com 39 itens. Atendendo ao reduzido tamanho da amostra, optámos por uma seleção menos exigente, mantendo alguns dos itens que não estavam correlacionados de forma significativa com o instrumento na sua globalidade, mas cuja exclusão conduziria a valores mais baixos da escala total e da dimensão de que faziam parte.

\section{O estudo final: caracterização da amostra}

Com a realização do pré-teste pretendíamos realizar uma abordagem preliminar à adequação da metodologia e ao comportamento psicométrico do instrumento de avaliação. Este, como verificámos apresentou índices de consistência interna satisfatórios, permitindo-nos avançar para um estudo final, abrangendo uma amostra mais extensa e diversificada de professores. No entanto, e tendo em conta que a construção de instrumentos de avaliação é um processo contínuo de análise das qualidades psicométricas das medidas elaboradas, recorremos novamente nesta fase ao cálculo dos coeficientes alfa de Cronbach para a escala total e para cada uma das dimensões e à análise fatorial, permitindo-nos obter evidências de validade de construto da escala, nomeadamente acerca da sua dimensionalidade.

Nesta fase, a população deste estudo contemplou professores de educação física a lecionar em diferentes escolas de Portugal. Distribuímos 260 questionários por diferentes escolas do país e após termos percorrido todas as etapas do processo tínhamos na nossa posse 206 questionários que foi considerado o $\mathrm{N}$ da nossa amostra e que correspondeu a uma taxa de retorno de $79.2 \%$, número suficiente para conduzir uma análise fatorial, tendo em conta o número de itens da escala (Stevens, 1986; Tinsley \& Tinsley, 1987).

Assim, fizeram parte da amostra do nosso estudo 206 professores, cuja caraterização por sexo, idade, instituição de formação inicial, tempo de serviço, situação profissional, habilitações académicas e outras atividades se encontra sistematizada na Tabela 2.
Tabela 2

Caracterização da amostra (estudo final)

\begin{tabular}{|c|c|c|}
\hline & $\mathrm{n}$ & $\%$ \\
\hline \multicolumn{3}{|l|}{ Sexo } \\
\hline Masculino & 120 & 58.8 \\
\hline Feminino & 84 & 41.2 \\
\hline \multicolumn{3}{|l|}{ Idade } \\
\hline$<25$ anos & 26 & 11.8 \\
\hline 26 a 35 anos & 83 & 37.7 \\
\hline 36 a 45 anos & 74 & 33.6 \\
\hline 46 a 55 anos & 34 & 15.5 \\
\hline$>55$ anos & 3 & 1.4 \\
\hline \multicolumn{3}{|c|}{ Instituição de Formação Inicial } \\
\hline INEF & 9 & 4.6 \\
\hline ISEF & 26 & 13.3 \\
\hline Faculdades & 107 & 54.9 \\
\hline ESEs & 53 & 27.2 \\
\hline \multicolumn{3}{|l|}{ Tempo de Serviço } \\
\hline$<3$ anos & 25 & 12.3 \\
\hline 4 a 6 anos & 25 & 12.3 \\
\hline 7 a 18 anos & 106 & 52.0 \\
\hline 19 a 30 anos & 34 & 16.7 \\
\hline$>30$ anos & 14 & 6.9 \\
\hline \multicolumn{3}{|l|}{ Habilitações Académicas } \\
\hline Bacharelato & 3 & 1.5 \\
\hline Licenciatura & 165 & 80.5 \\
\hline Mestrado & 35 & 17.0 \\
\hline Doutoramento & 2 & 1.0 \\
\hline \multicolumn{3}{|l|}{ Outras Atividades } \\
\hline Ginásios & 32 & 23.0 \\
\hline Clubes & 75 & 54.0 \\
\hline Animação Desportiva & 7 & 5.0 \\
\hline Outros & 25 & 18.0 \\
\hline \multicolumn{3}{|l|}{ Situação Profissional } \\
\hline Contratado & 50 & 28.4 \\
\hline P.Q. Zona Pedagógica & 33 & 18.8 \\
\hline P. Q. Nom. Definitiva & 93 & 52.8 \\
\hline
\end{tabular}

Como podemos verificar na Tabela 2 , dos 206 professores de Educação Física de diferentes escolas do país que participaram na investigação, $41.3 \%$ são do sexo feminino e $58.7 \%$ do sexo masculino. Relativamente à idade, $40.3 \%$ dos professores encontram-se entre os 26 e 35 anos, seguindo-se as faixas etárias, dos 36 aos 
45 anos com $35.9 \%$ dos professores e a dos 46 aos 55 anos, com $16.5 \%$. Observamos, também, que apenas $5.6 \%$ dos inquiridos têm idade inferior a 25 anos e $1.5 \%$ idade superior a 56 anos. Notamos, pois, por estes dados que, pelo menos, $75 \%$ dos professores que constituem a amostra têm idade inferior a 45 anos, sendo, pois, um grupo de professores ainda não muito envelhecido.

Por sua vez, no que diz respeito à instituição de formação inicial foram obtidas 195 respostas. Como seria de esperar o número de diplomados pelo Instituto Nacional de Educação Física é muito pouco expressivo, representando apenas $4.5 \%$ dos professores da amostra, o que não deixa de ser um número razoável, tendo em conta o número muito limitado de professores formados por esta escola ainda no ativo. O mesmo se aplica aos diplomados pelos Institutos Superiores de Educação Física de Lisboa e do Porto que representam uma minoria de professores no ativo, que se traduziu na nossa amostra numa percentagem de $13.3 \%$. Como seria expectável a maioria dos inquiridos $54.9 \%$ fizeram a sua formação nas instituições mais recentes, nomeadamente no ensino universitário, público e privado, e $27.2 \%$ no ensino politécnico, concretamente em escolas superiores de educação.

No que diz respeito às habilitações académicas, observamos que a maioria dos professores inquiridos, $80.5 \%$, tem como grau académico a licenciatura, enquanto $17 \%$ possuem mestrado, $1 \%$ o grau de doutor e apenas $1.5 \%$ tem o grau de bacharelato. A maioria dos professores que constitui a amostra do estudo, $67.5 \%$, referiu ainda que possui outras atividades profissionais ligadas à educação física. Entre estes profissionais, $54 \%$, afirmaram exercer atividades em clubes e $23 \%$ em ginásios, tendo apenas $5 \%$ respondido exercer atividades de animação desportiva, enquanto $18 \%$ disseram participar/pertencer a outros espaços não nomeados.

Finalmente, no respeitante à situação profissional, e diretamente relacionado com o tempo de serviço, $28.4 \%$ dos professores estão em regime de contrato, enquanto $52.8 \%$ são professores do quadro de nomeação definitiva e $18.8 \%$ pertencem ao quadro de zona pedagógica.

\section{Instrumento}

A escala, depois de modificada e adaptada, fruto da nossa reflexão pessoal, após a consulta a especialistas e à literatura da área, dos prétestes efetuados e dos estudos de validade e fidelidade realizados (e.g., análise da consistência interna, análise fatorial exploratória e confirmatória), deu origem à versão final que a seguir apresentamos com uma estrutura segundo o modelo da escala de tipo Likert, a exigir que os professores respondam de acordo com as seguintes alternativas: Discordo Totalmente (DT): 1, Discordo (D): 2, Nem Concordo/Nem Discordo (NC/ ND): 3, Concordo (C): 4 e Concordo Totalmente (CT): 5 (Anexo 1).

A primeira dimensão, Envolvimento Pedagógico, composta por seis itens (Tabela 3), trata-se de uma dimensão fulcral na definição da identidade do professor de educação física, relacionando-se com a perceção do seu envolvimento no processo pedagógico, composta por itens relacionados com a forma como define o seu trabalho, como se relaciona com os seus alunos e, sobretudo, como se perceciona enquanto professor.

Por sua vez, a segunda dimensão, designada de Motivacional, composta por cinco itens (Tabela 4), aponta para os aspetos motivacionais relacionados com a prática profissional.

\section{RESULTADOS}

No que diz respeito aos estudos de fidelidade e validade da escala, realizámos a sua análise em duas etapas distintas. Numa primeira etapa, com o objetivo de avaliar as propriedades dos itens calculámos as suas médias, desvios-padrão e correlação com a escala (excetuando o item 3) e realizámos a análise da consistência interna através do coeficiente alfa de Cronbach. Numa segunda etapa, realizámos o processo de validação da escala, avaliando os resultados das análises fatoriais a que foram 
submetidos. Optámos por esta análise, porque este método é considerado como um dos mais eficazes e poderosos, sendo, frequentemente, utilizado com instrumentos de avaliação psicológica, a fim de calcular a sua adequação para medir a dimensão que pretende avaliar (Bryan \& Cramer, 1993; Cronbach, 1984; Nunnally, 1978; Stevens, 1986; Tinsley \& Tinsley, 1987).

Tabela 3

Itens da Dimensão Envolvimento Pedagógico

Itens

1. Sou um(a) professor(a) responsável e empenhado que me esforço por desenvolver as capacidades dos meus alunos

3. Sou um(a) professor(a) que me preocupo com o bem-estar físico e psicológico dos alunos.

4. Sou um(a) professor (a) e que me empenho bastante preparando as aulas com rigor e de uma forma metódica.

6. Essencialmente o que me levou a optar pela docência foi o gosto por transmitir conhecimentos aos mais jovens.

8. Tento sempre evoluir como profissional aprendendo com os professores mais velhos.

11. Uma aula ideal de educação física é aquela que consegue responder às motivações dos alunos e que é orientada por objetivos previamente definidos.

Tabela 4

Itens da Dimensão Motivacional

\section{Itens}

2. Estou muito motivado para a docência.

5. Enquanto tiver vontade de aprender nada abalará a minha motivação.

7. Estou motivado(a), porque gosto imenso de me relacionar com as crianças e os jovens.

9. Ensino com muito gosto, porque tenho uma enorme paixão pela área da educação física e do desporto.

10. Sou um(a) professor(a) entusiasta.

No presente estudo, a validade fatorial do instrumento foi inicialmente avaliada através da análise de componentes principais (ACP), e, posteriormente, através da análise fatorial confirmatória, testando um modelo de dois fatores, que emergiram como interpretáveis a partir da análise fatorial exploratória, sendo que revelaram igualmente indicadores de consistência interna bastante satisfatórios, considerando o número relativamente reduzido de itens das duas dimensões, designadamente a de Envolvimento Pedagógico e a Motivacional.

\section{Análise da consistência interna}

A análise dos itens permitiu-nos verificar que dos 39 itens apenas os itens 5, 6, 13, 14, $17,18,19,21,22,25,29,30,36$ e 37 se correlacionam com a escala total de forma significativa (valores > a 0.30; ver Tabela 5).

Todos os outros apresentaram valores de magnitude baixa ou moderada, por isso optámos por eliminá-los. Após a sua eliminação, foi encontrado um alfa de Cronbach para a escala total de 0.81 , valor que se pode considerar bastante razoável.

\section{Análise fatorial exploratória}

Para avaliar a dimensionalidade da escala da EIPPEF recorremos à análise fatorial exploratória, em componentes principais, com rotação Varimax. Os resultados revelaram uma estrutura em três fatores com valores próprios superiores a 1, explicando $50.08 \%$ da variância dos resultados. Na tabela 6 é apresentada a distribuição final dos itens pelos referidos fatores, bem como os seus valores de saturação.

O primeiro fator, designado por Envolvimento Pedagógico, agrupa os itens 13, 19, 21, 25, 29 e 37, explica $19.6 \%$ da variância; o segundo fator, denominado de Motivacional agrupa os itens $5,14,22,30$ e 36 , explica $18.75 \%$ da variância; o terceiro fator, que agrupa os itens 6, 17 e 18, explica $11.73 \%$, mas não se revelou muito interpretável. Importa, no entanto, sublinhar que os dois fatores emergentes da análise fatorial mostraram-se internamente consistentes, apresentando alfas de Cronbach no valor de 0.73 e 0.78 , respetivamente.

\section{Análise fatorial confirmatória}

As medidas de avaliação do ajustamento para verificar a adequabilidade do modelo aos resultados foram as seguintes: chi square $\left(\mathrm{X}^{2}\right)$, 
Tabela 5

Estatísticas relativas à fidelidade da EIPPEF

\begin{tabular}{cccc}
\hline Item & $\begin{array}{c}\text { Correlação } \\
\text { Item-total }\end{array}$ & Item & $\begin{array}{c}\text { Correlação } \\
\text { Item-total }\end{array}$ \\
\hline 5 & $0.32^{* *}$ & 21 & $0.38^{* *}$ \\
6 & $0.32^{* *}$ & 22 & $0.45^{* *}$ \\
13 & $0.31^{* *}$ & 25 & $0.32^{* *}$ \\
14 & $0.42^{* *}$ & 29 & $0.44^{* *}$ \\
17 & $0.30^{* *}$ & 30 & $0.37^{* *}$ \\
18 & $0.33^{* *}$ & 36 & $0.44^{* *}$ \\
19 & $0.48^{* *}$ & 37 & $0.36^{* *}$ \\
\hline
\end{tabular}

Nota: ${ }^{* *} p<0.01$

Tabela 6

Matriz fatorial da EIPPEF

\begin{tabular}{|c|c|c|c|}
\hline Item & Fator 1 & Fator 2 & Fator 3 \\
\hline 5 & & 0.80 & \\
\hline 6 & & & 0.67 \\
\hline 13 & 0.70 & & \\
\hline 14 & & 0.80 & \\
\hline 17 & & & 0.56 \\
\hline 18 & & & 0.71 \\
\hline 19 & 0.44 & & \\
\hline 21 & 0.75 & & \\
\hline 22 & & 0.71 & \\
\hline 25 & 0.60 & & \\
\hline 29 & 0.47 & & \\
\hline 30 & 0.48 & 0.51 & \\
\hline 36 & & 0.45 & \\
\hline 37 & 0.64 & & \\
\hline Valor próprio & 2.774 & 2.624 & 1.642 \\
\hline \% da Variância explicada & 19.60 & 18.75 & 11.73 \\
\hline
\end{tabular}

ratio chi square statistics/degrees of freedom ( $\left.\mathrm{X}^{2} / \mathrm{df}\right)$, comparative fit index (CFI), goodness of fit index (GFI), adjusted goodness of fit index (AGFI) e root mean square error of approximation (RMSEA).

Os resultados revelaram um $\mathrm{X}^{2}$ significativo (67.56, $\mathrm{df}=43, p<0.001)$, sugerindo que o modelo em estudo não se adequa aos dados. No entanto, considerando que o $\mathrm{X}^{2}$ é bastante sensível ao tamanho da amostra, muitos investigadores têm sugerido a utilização do rácio
$\mathrm{X}^{2} / \mathrm{df}$, havendo algum consenso para se considerar valores inferiores a 3 como satisfatórios. No presente estudo o rácio $\mathrm{X}^{2} / \mathrm{df}$ foi de 1.57 , revelando um ajustamento adequado. Os outros indicadores de ajustamento, designadamente o CFI com um valor de 0.951, o GFI com 0.942 , o AGFI com 0.911 e o RMSEA com 0.053 sugerem, igualmente, que o modelo com dois fatores se ajusta aos dados, confirmando uma estrutura em duas dimensões na avaliação 
da identidade profissional dos professores de educação física. Temos, assim, como primeiro fator o Envolvimento Pedagógico, que compreende os itens 13, 19, 21, 25, 29 e 37 e como segundo fator o Motivacional, que compreende os itens $5,14,22,30$ e 36 .

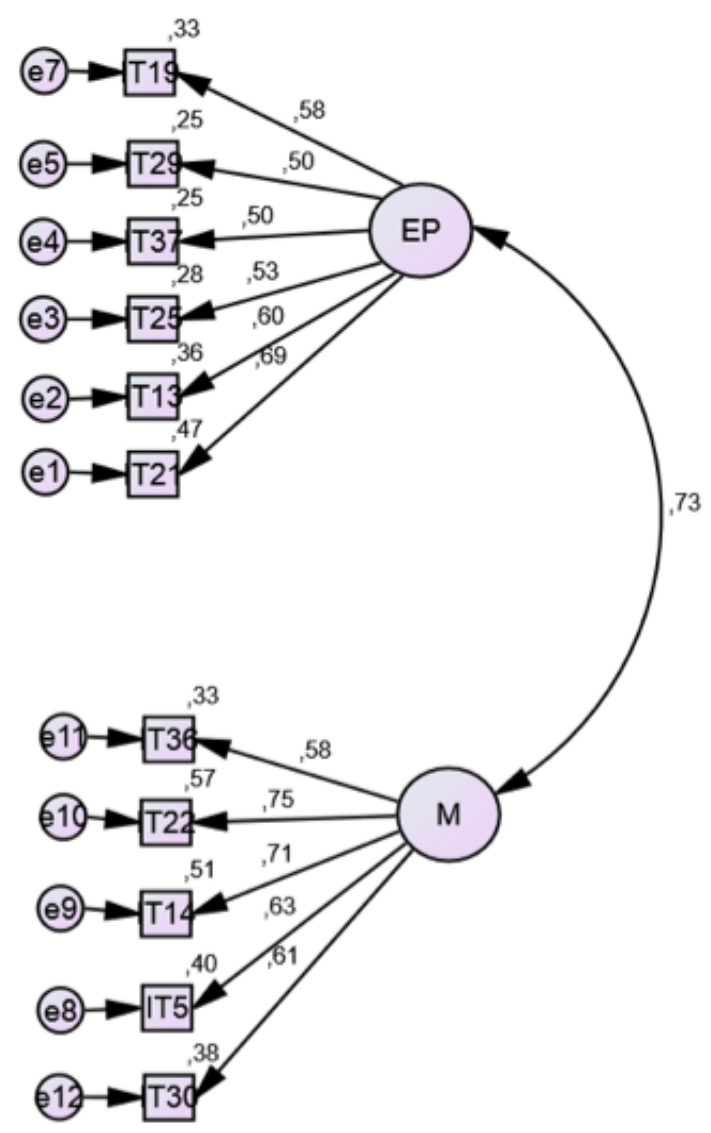

Figura 1. Modelo final proposto

\section{DISCUSSÃO}

Numa sociedade onde a mudança ocupa um lugar central, a compreensão da identidade profissional docente tem de considerar, necessariamente, o professor em exercício em ambiente profissional e formativo, ou seja, tem de considerar a existência de uma identidade que é criada tanto no palco da profissão, como no palco da formação (inicial e contínua) porque não pode deixar de estar sujeita à influência das experiências pessoais e profissionais (Borges, 2003; Lahire, 2002; Rezer, 2007).

Ora a indagação da identidade profissional do professor de educação física, nestes diferen- tes palcos, afigura-se como uma tarefa complicada, porque estudar a sua identidade profissional implica também o reconhecimento da heterogeneidade que carateriza este grupo disciplinar. Assim, desde as diferenças individuais dos percursos de formação inicial e contínua até às afinidades grupais que distinguem, aproximam ou opõem uns professores em relação aos outros no seio do mesmo grupo disciplinar, é possível encontrar uma grande diversidade de variáveis que sustentam esta heterogeneidade (Moreira \& Ferreira, 2011). A proliferação dos cursos a partir da década de noventa e que se foram apresentando com designações diferenciadas, em várias instituições do setor estatal e do domínio privado, concorreram para a heterogeneidade da identidade dos professores de educação física (Moreira, 2013). Sendo numerosas as variáveis que concorrem para esta heterogeneidade, podendo considerar-se, entre outras, o nível de ensino em que os professores lecionam, a situação profissional, a habilitação académica, o tempo de serviço e a posição na carreira, a experiência profissional, entendemos importante estabelecer o que os define como docentes no espaço de educação formal.

Motivados, pois, por esta complexa tarefa procurámos desenvolver um estudo que possibilitasse indagar a forma como estes professores de educação física, provindo de diferentes escolas de formação existentes em Portugal desde a década de 40 do século XX, se percecionam no exercício da sua profissão e se afirmam enquanto docentes de uma disciplina singular no contexto escolar. Diante da dificuldade de encontrar um instrumento específico fidedigno para avaliar a identidade dos professores de educação física, o que, de algum modo, se alinha diante da ideia de outros investigadores que referem a escassez de estudos relacionados com a identidade profissional destes docentes (Dowling, 2006, 2011; Gomes et al., 2013), decidimos construir uma escala de avaliação da identidade profissional para este grupo disciplinar, inspirados, sobretudo, nos estudos desenvolvidos por Kelchtermans 
(1993, 1995), que se revelaram determinantes para o desencadear da etapa inicial da exploração e clarificação das principais dimensões da identidade docente.

Após a realização de um pré-teste, e posteriormente administrada a Escala de Identidade Profissional de Professores de Educação Física, a uma amostra de 206 professores de educação física, concluiu-se que o instrumento possui qualidades psicométricas satisfatórias. A análise da consistência interna dos dois fatores identificados - Envolvimento Pedagógico e Motivacional - revelou que se trata de um instrumento fidedigno. Ora, uma vez que estes fatores se apresentam internamente consistentes, bem definidos pelos itens, concluímos que a escala revela qualidades psicométricas pelo que nos parece interessante o seu uso em futuros estudos a desenvolver nesta área.

Na verdade, para além de bons indicadores de validade, globalmente, as medidas aplicadas caraterizam-se por uma fidelidade que consideramos boa ou adequada e com estruturas fatoriais interpretáveis, pressupondo, portanto, que avaliam, de forma consistente, as variáveis que pretendem medir, constituindo-se como uma escala capaz de contribuir para o esclarecimento da identidade profissional dos professores de educação física.

\section{CONCLUSÕES}

Em síntese, podemos afirmar que o instrumento de investigação que construímos é válido para avaliar a identidade profissional destes professores, medindo duas dimensões distintas deste construto: a dimensão Envolvimento Pedagógico relacionada com a forma como o professor define o seu trabalho, como se relaciona com os alunos e, sobretudo como se perceciona enquanto profissional e a dimensão Motivacional que aponta para aspetos motivacionais relacionados com a prática profissional.

Agradecimentos:

Nada a declarar.

\section{Conflito de Interesses:}

Nada a declarar.

\section{Financiamento:}

Estudo apoiado pela Fundação para a Ciência e a Tecnologia (FCT).

\section{REFERÊNCIAS}

Borges, C. (2003). O professor de educação física e a construção do saber. Campinas: Papirus.

Bryan, A., \& Cramer, D. (1993). Análise de dados em ciências sociais: Introdução às técnicas utilizando o SPSS. Oeiras: Celta Editora.

Cronbach, L. (1984). Essencial of psychological testing. New York: Harper \& Row.

Dowling, F. (2006). Physical education teacher educators' professional identities, continuing professional development and the issue of gender equality. Physical Education and Sport Pedagogy, 3, 247-263.

Dowling, F. (2011). Are PE teacher identities fit for postmodern schools or are they clinging to modernist notions of professionalism? Sport, Education and Society, 2, 201-222. doi: 10.1080/ 13573322.2011.540425

Ferreira, A. G., \& Moreira, J. A. (2010). A autoestima profissional dos professores de Educação Física em Portugal. Exedra, 4, 65-80.

Ferreira, A. G., \& Moreira, J. A. (2012). Perceptions of Pedagogical Practices of Physical Education Teachers in Portugal since the 1970s. SportLogia Journal, 8, 21-28. doi: 10.5550/sgia.120801. en.021F

Ferreira, A. G., Moreira, J. A., \& Ferreira, J. A. (2011). Percepções sobre o Estatuto Socioprofissional dos Professores de Educação Física em Portugal. Revista Portuguesa de Pedagogia, ExtraSérie, 205-223.

Gomes, P., Ferreira, C., Pereira, A., \& Batista, P. (2013). A identidade profissional do professor: Um estudo de revisão sistemática. Revista Brasileira de Educação Física e Esporte, 27(2), 247-267. doi: 10.1590/S1807-55092013000200009

Kelchtermans, G. (1993). Getting the story, understanding the lives: From career stories to teacher's professional development. Teaching and Teacher Education, 9, 443-456. 
Kelchtermans, G. (1995). A utilização de biografias na formação de professores. Aprender, 18, 5-20.

Lahire, B. (2002). O homem plural: Os determinantes da acção. Petrópolis: Vozes.

Moreira, J. (2013). Perspetiva Histórico-Contemporânea da Educação Física em Portugal. Santo Tirso: DeFacto Editores.

Moreira, J. A., \& Ferreira, A. G. (2011). A Identidade Socioprofissional dos Professores de Educação Física em Portugal. e-curriculum, 7, 1-21.

Moreira, J. A., \& Ferreira, A. G. (2012). A autoimagem profissional dos professores de Educação Física em Portugal. Educação \& Realidade, 37, 741-763.

Nunnaly, J. C. (1978). Psychometric theory. New York: McGraw-Hill.

Oliveira, J. (2012). O Ensino da Educação Física em Portugal: Difusão e Implementação da Ginástica Sue- ca em Portugal na Primeira Metade do Século XX. Dissertação de Doutoramento não publicada. Universidade de Coimbra, Portugal.

Oppenheim, A. (1979). Questionnaire design and attitude measurement. Grã-Bretanha: Morrison \& Gibb.

Pestana, M., \& Gageiro, J. (2003). Análise de dados para as Ciências Sociais - A complementaridade do SPSS ( $3^{\mathrm{a}}$ ed). Lisboa: Edições Sílabo.

Rezer, R. (2007). Relações entre conhecimento e prática pedagógica no campo da Educação Física: Pontos de vista. Motrivivência, 19, 38-62.

Stevens, J. (1986). Applied multivariate statistics for the social sciences. New Jersey: Lawrence Erlbaum Associates.

Tinsley, H., \& Tinsley, D. (1987). Uses of factor analysis in counseling psychology research. Journal of Counseling Psychology, 34, 414-424. 


\section{ANEXO 1}

\section{ESCALA DE IDENTIDADE PROFISSIONAL DE PROFESSORES DE EDUCAÇÃO FÍSICA (EIPPEF) Moreira, Ferreira \& Ferreira (2014)}

As afirmações que se seguem inscrevem-se em perceções que se relacionam com a identidade profissional dos docentes de educação física.

Indique o seu grau de acordo ou desacordo com as afirmações ${ }^{1}$, usando a seguinte escala:

\begin{tabular}{|c|c|c|c|c|}
\hline 1 & 2 & 3 & 4 & 5 \\
\hline $\begin{array}{c}\text { Discordo Totalmente } \\
\text { (DT) }\end{array}$ & $\begin{array}{c}\text { Discordo } \\
\text { (D) }\end{array}$ & $\begin{array}{c}\text { Nem Concordo/ } \\
\text { Nem Discordo } \\
\text { (NC/ND) }\end{array}$ & $\begin{array}{c}\text { Concordo } \\
\text { (C) }\end{array}$ & $\begin{array}{c}\text { Concordo Totalmente } \\
\text { (CT) }\end{array}$ \\
\hline
\end{tabular}

Itens

DT $\quad \mathrm{D} \underset{\mathrm{ND}}{\mathrm{NC} /} \mathrm{C} \quad \mathrm{CT}$

1. Sou um(a) professor(a) responsável e empenhado que me esforço por desenvolver as capacidades dos meus alunos.

2. Estou muito motivado para a docência.

3. Sou um(a) professor(a) que me preocupo com o bem-estar físico e psicológico dos alunos.

$\begin{array}{lllll}1 & 2 & 3 & 4 & 5 \\ 1 & 2 & 3 & 4 & 5 \\ 1 & 2 & 3 & 4 & 5 \\ 1 & 2 & 3 & 4 & 5 \\ 1 & 2 & 3 & 4 & 5 \\ 1 & 2 & 3 & 4 & 5 \\ 1 & 2 & 3 & 4 & 5 \\ 1 & 2 & 3 & 4 & 5 \\ 1 & 2 & 3 & 4 & 5 \\ 1 & 2 & 3 & 4 & 5 \\ 1 & 2 & 3 & 4 & 5\end{array}$

4. Sou um(a) professor(a) e que me empenho bastante preparando as aulas com rigor e de uma forma metódica.

5. Enquanto tiver vontade de aprender nada abalará a minha motivação.

6. Essencialmente o que me levou a optar pela docência foi o gosto por transmitir conhecimentos aos mais jovens.

7. Estou motivado(a), porque gosto imenso de me relacionar com as crianças e os jovens.

8. Tento sempre evoluir como profissional aprendendo com os professores mais velhos.

9. Ensino com muito gosto, porque tenho uma enorme paixão pela área da educação física e do desporto.

10. Sou um(a) professor(a) entusiasta.

11. Uma aula ideal de educação física é aquela que consegue responder às motivações dos alunos e que é orientada por objetivos previamente definidos.

Nota: ${ }^{1}$ Tendo em consideração que foram eliminados itens da escala inicial, foi atribuída uma nova numeração aos itens da escala final que ficou, no total, com 11 itens. Assim, o item 1 corresponde ao item 13 da escala inicial; o item 2 ao item 5; o item 3 ao item 21; o item 4, ao item 29; o item 5 ao item 14; o item 6 ao item 19; o item 7 ao item 22; o item 8 ao item 25; o item 9 ao item 30; o item 10 ao item 36; e o item 11 ao item 37, respetivamente. Para uma versão original da escala com 40 itens consultar o autor correspondente.

Todo o conteúdo da revista Motricidade está licenciado sob a Creative Commons, exceto quando especificado em contrário e nos conteúdos retirados de outras fontes bibliográficas. 